\title{
Study on the Instability Mechanism of Large Dip Roadway in the Coal Seam
}

\author{
Zhiwei Feng1, Peng $\mathrm{Wu}^{2}$, Liang Chen ${ }^{3}$ \\ ${ }^{I}$ School of Mechanics and Civil Engineering, China University of Mining \& Technology, Xuzhou221116, China \\ ${ }^{2}$ State Key Laboratory for Geomechanics and Deep Underground Engineering, China University of Mining \& \\ Technology, Xuzhou221116, China \\ ${ }^{3}$ State Key Laboratory of Coal Resources and Safe Mining, China University of Mining \& Technology, \\ Xuzhou221116, China
}

*Corresponding Author: Zhiwei Feng,, School of Mechanics and Civil Engineering, China University of Mining \& Technology, Xuzhou221116, China

\begin{abstract}
Roadway with weak surface in roof is a common type of roadway in coal mining. Under the action of high stress, the shear slip of weak surface is easy to cause shear failure of roadway roof and supporting structure, and cause the overall instability of roadway. Especially under the condition of large dip angle, the degree of weak surface sliding is more severe, and the influence on roadway is more significant. In this paper, based on the engineering background of a large inclined haulage roadway in a mine, using FLAC3D numerical calculation software, considering the two situations of roof with and without weak surface, the evolution laws of shear displacement of weak surface, displacement of surrounding rock of roadway and plastic zone under different coal seam dip angles are compared and analyzed, and the instability mechanism of roadway in large dip angle coal seam under complex stress environment is revealed. The main conclusions are as follows: the maximum shear displacement When there is no weak surface, the maximum deformation of roadway changes from left side > roof > floor > right side to floor > roof or left side > right side under the inclination angle of $45^{\circ} \mathrm{C}$; with the increase of dip angle, the plastic zone expansion trend extends along the coal rock tendency from horizontal and vertical directions; when considering the weak surface effect, the maximum deformation of roadway changes from the change trend of left side > roof > floor > right side At the same time, the maximum deformation of roadway under any dip angle presents the change characteristics of roof > left side > floor or right side, and the roof deformation is mainly the right arch shoulder. The plastic zone expansion trend is basically consistent with the situation without weak surface, but the range is larger than the former.
\end{abstract}

Keywords: weak surface; steep coal seam; instability mechanism; numerical calculation

\section{INTRODUCTION}

At present, scholars at home and abroad have carried out a large number of studies on the instability mechanism of large dip roadway under different geological conditions. Under the influence of excavation disturbance and mining movement, the deformation and failure characteristics of large-dip coal seam mining roadway are as follows ${ }^{[1-12]}$ :(1) The deformation and plastic zone distribution of roadway are asymmetric. (2)Floor heave is prominent. (3)The problem of roadway spalling is obvious. (4)Large span thin roof roadway is prone to shear-slip failure along the weak surface of rock strata. The high stress area of coal roadway with large dip angle is mainly concentrated in the upper part of high slope and the lower part of lower side, and the stress distribution shows obvious asymmetry, which is mainly reflected in the following aspects ${ }^{[13-16]}$ :(1) Asymmetric deformation failure of "topside collapse"; (2) Diagonal tension and shear failure formed by high top Angle and low bottom Angle; The results of field measurement and UDEC numerical simulation show that ${ }^{[17]}$ the failure mode of the side of mining roadway in large inclined seam is circular shear slip failure, and the damage degree of high slope is obviously greater than that of low slope; 
Theoretical analysis and FLAC3D numerical simulation results show that ${ }^{[18]}$ the surrounding rock fracture of roadway is mainly caused by the shear and tension of the upper strata of the roof, and then gradually extends to both sides of the roadway, resulting in the overall instability of the roadway; The problems frequently encountered in the mining process of steeply dipping coal seam are summarized as follows ${ }^{[19-35]}$ : (1) The roof caving rock is easy to slide along the inclined direction of the rock stratum, which forms a non-uniform filling area in the goaf, which leads to the increase of the ground pressure above the working face and increases the difficulty of the control of the upper working face. (2) The serious spalling of coal wall in working face leads to systematic linkage instability of roof and coal wall, then it induces the occurrence of geological disasters such as large area caving and coal wall spalling. (3) The problem of floor heave in working face is prominent, which is easy to cause systematic instability of "Roof - Support - Floor" (R-S-F). (4)When the coal seam inclination angle is large, the hydraulic support on the working face is prone to slip and instability, toppling, biting, squeezing and so on.

The roadway with weak surface in roof is a common type of roadway in coal mining. Under high stress, the shear slip of weak surface is easy to cause shear failure of roadway roof and supporting structure, and cause the overall instability of roadway, especially under the condition of large dip angle, the degree of weak surface sliding is more severe, the influence on roadway is more significant. However, there are few reports on the instability mechanism of large dip roadway considering the influence of weak surface slip, this article will supplement it. Mining intensity is also an important factor affecting the instability of surrounding rock structure of roadway, therefore, the study on the instability mechanism of roadway with weak surface in roof of large inclined coal seam under mining can provide important reference for support design of such roadway.

In this paper, based on the engineering background of a large dip angle haulage roadway of a mine, FLAC3D simulation software is used to establish the numerical simulation model of large angle coal seam roadway considering the roof with and without weak surface. The surrounding rock displacement, weak surface shear displacement and plastic zone evolution law of roadway in large dip angle coal seam under different coal seam dip angles are compared and analyzed, so as to reveal the evolution mechanism of roadway failure and instability in high angle coal seam under complex stress environment.

\section{OVERVIEW OF ENGINEERING GEOLOGY}

A mine field is $2.33 \mathrm{~km}$ long from north to south, $1.25 \mathrm{~km}$ wide from east to west, with an area of $3.0801 \mathrm{~km}^{2}$. The overall terrain is high in the east and west, low in the middle, high in the north and low in the south. The highest point is located in the northeast of the mine field, with an elevation of $1719.5 \mathrm{~m}$, and the lowest point is located in the southwest of the mine field, with an elevation of 1430 $\mathrm{m}$ and a maximum relative height difference of $289.5 \mathrm{~m}$. 1201 working face is located in 2\# coal seam, which is a thick coal seam with stable sedimentation and complex structure. Its thickness is within $6 \sim 8 \mathrm{~m}$, with an average coal thickness of $6.8 \mathrm{~m}$ and an average dip angle of $45^{\circ}$. In addition, the average buried depth of the coal seam is $400 \mathrm{~m}$, and the direct roof is clay rock and $\mathrm{K} 3$ sandstone, with soft lithology; The coal seam floor is argillaceous siltstone, which has the characteristics of low strength and easy softening when meeting water. Generally speaking, the rock properties of coal seam and roof and floor slab of 1201 working face are weak, which belongs to the typical three soft thick coal seam with large dip angle. The 1201 transport roadway is excavated in the working face of the coal seam. The roadway section shape is straight wall semicircular arch, the roadway width is $4.3 \mathrm{~m}$, and the wall height is $2 \mathrm{~m}$. The comprehensive histogram of the coal seam is shown in Fig. 1. 
Study on the Instability Mechanism of Large Dip Roadway in the Coal Seam

\begin{tabular}{|c|c|c|c|}
\hline histogram & lithology & thickness/m & Lithology description \\
\hline & overlying rock & --- & -- \\
\hline & Medium fine sandstone & 13.2 & Light grey -dark grey \\
\hline & Medium sandstone & 5.3 & Light gray -grayish white, uneven cementation \\
\hline & Siltstone & 4.2 & Gray, with certain horizontal joints \\
\hline & K3 sandstone & 5.0 & Light gray, small karst can be seen locally \\
\hline & Coarse sandstone & 5.7 & Dark gray - gray, massive structure and undeveloped bedding \\
\hline & K3 sandstone & 2.0 & Light gray, small karst can be seen locally \\
\hline & Clay rock & 0.8 & It contains plant root fossils and is easy to separate the upper strata \\
\hline & 2\#coal seam & 6.8 & Black-dark black, asplaalt glass luster \\
\hline & pelitic siltstone & 1.0 & $\begin{array}{l}\text { The upper part contains plant root fossils, which are easy to expand } \\
\text { and soften when encountering water }\end{array}$ \\
\hline & Siltstone & 2.6 & Grey - dark grey \\
\hline & coal seam & 1.0 & Dark gray-grayish black, with high carbon content in the upper part \\
\hline & Medium sandstone & 12.0 & Light gray-grayish white, uneven cementation \\
\hline & Overlying strata & --- & -- \\
\hline
\end{tabular}

Fig1. Comprehensive histogram of $2 \#$ coal seam

\section{NUMERICAL CALCULATION MODEL AND SCHEME}

\subsection{Numerical Calculation Model}

Taking the transportation roadway of 1201 working face of a mine as the engineering background, combined with the comprehensive histogram of $2 \#$ coal seam shown in Fig. 1, the numerical simulation calculation model is established. Fig. 2(a) presents the schematic diagram of the numerical model built this time. It can be seen from the figure that the length $\times$ width $\times$ height of the model built this time $=180 \mathrm{~m} \times 90 \mathrm{~m} \times 120 \mathrm{~m}$, in which the working face is $55 \mathrm{~m}$ long, the coal seam inclination angle is $45^{\circ}$, and the full height of the first mining. Fig. 2(b) presents a schematic diagram of the boundary conditions of the model, in which all the sides and the bottom of the model are fixed displacement constraints, and the top is stress boundary conditions. As the average buried depth of the roadway is $400 \mathrm{~m}$ and calculated according to the average bulk density of $25 \mathrm{kN} / \mathrm{m}^{3}$, the vertical pressure applied to the upper boundary of the model is 10.0 MPa. According to the test results of insitu stress, the lateral pressure coefficient is set as 1.5, and the coal and rock strength is assumed to meet the Mohr-Coulomb criterion.

The return air roadway and transport roadway on 1201 working face are located in the middle of the coal seam. The section shape of the roadway is straight wall semicircle arch, in which the return air roadway drives along the floor of the coal seam and the transport roadway drives along the middle of the coal seam. The size of the return air roadway model is wide $\times$ wall height $=3.8 \mathrm{~m} \times 2 \mathrm{~m}$, and the width $\times$ wall height of the transport roadway $=4.3 \mathrm{~m} \times 2 \mathrm{~m}$. Fig. 3 shows the $3 \mathrm{D}$ numerical calculation model established in this simulation. In order to eliminate the boundary effect, coal pillars with a width of $55 \mathrm{~m}$ and $60 \mathrm{~m}$ are left on the left and right sides of the working face. In addition, in order to improve the calculation accuracy, the coal seam, the direct top and the direct bottom grids are all encrypted. Assume that the periodic pressure step is $10 \mathrm{~m}$, the goaf and the corresponding roadway are backfilled and filled every $10 \mathrm{~m}$ to simulate the effect of periodic weighting on the main roof caving.

Table 1 shows the physical and mechanical parameters of each rock layer in the simulation. In order to simulate the stoping process, the model adopts the step-by - step excavation mode. The step distance of excavation is $10 \mathrm{~m}$ from $\mathrm{Y}=15 \mathrm{~m}$, a total of 6 times, so the working face is pushed forward $60 \mathrm{~m}$ in total. It should be noted that, in order to simulate the effect of sliding effect of the weak surface of the roof on the instability mechanism of large-dip roadway, the interface between coal body and clay rock of the 1201 transport roadway was set as the contact element for the study, in which the weak surface shear stiffness and normal stiffness were both set at $2.0 \mathrm{GPa}$, and the friction angle and cohesion were respectively set at $15^{\circ}$ and $0.1 \mathrm{MPa}$. 


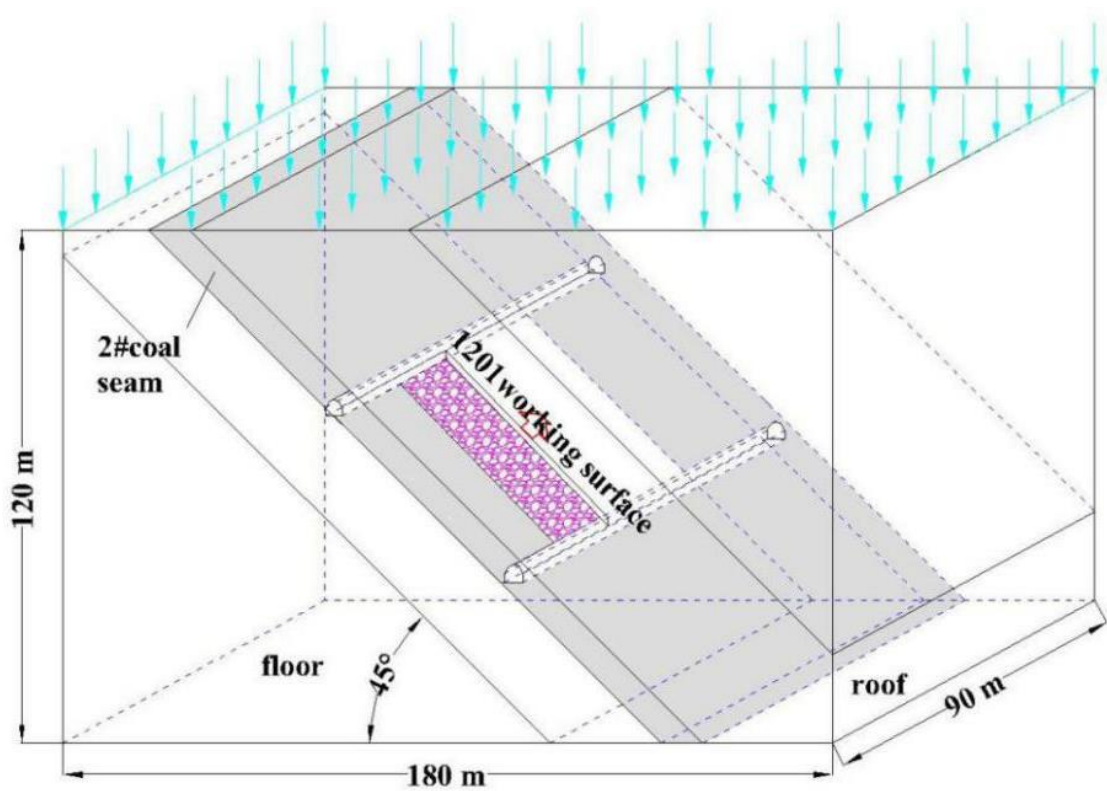

(a) Schematic diagram of numerical calculation model

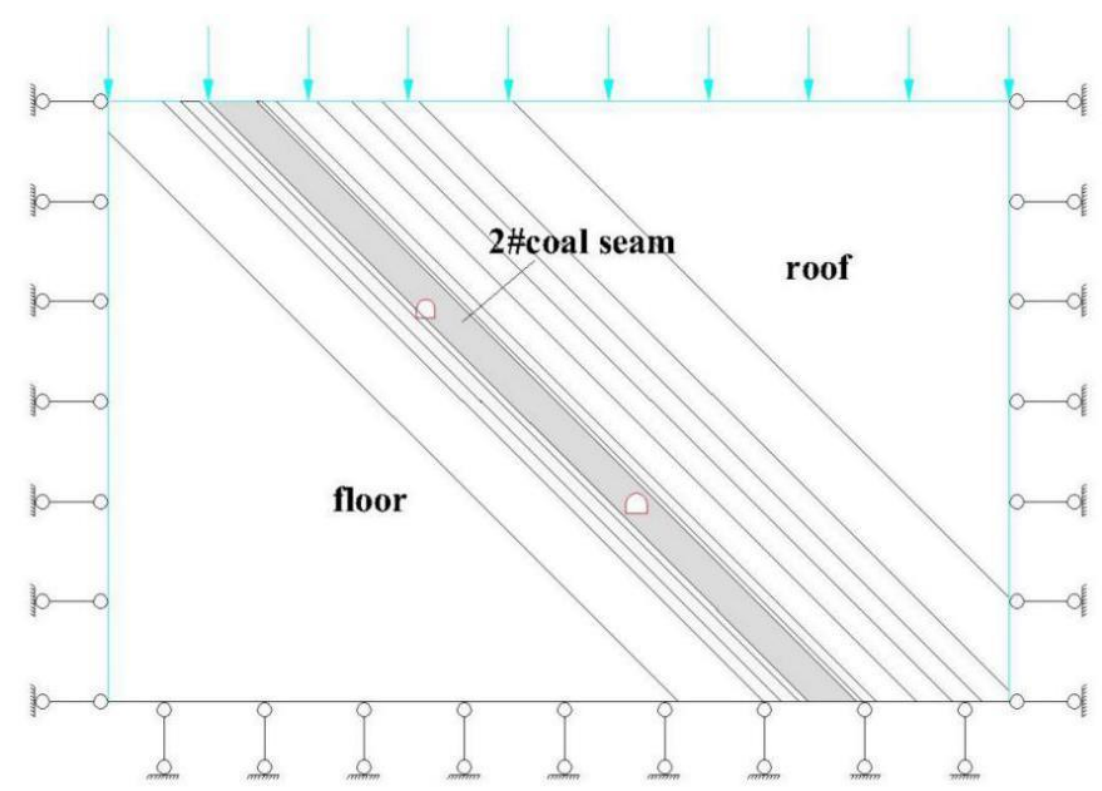

(b) Schematic diagram of model boundary conditions

Fig2. Schematic diagram on the numerical simulation model and boundary condition

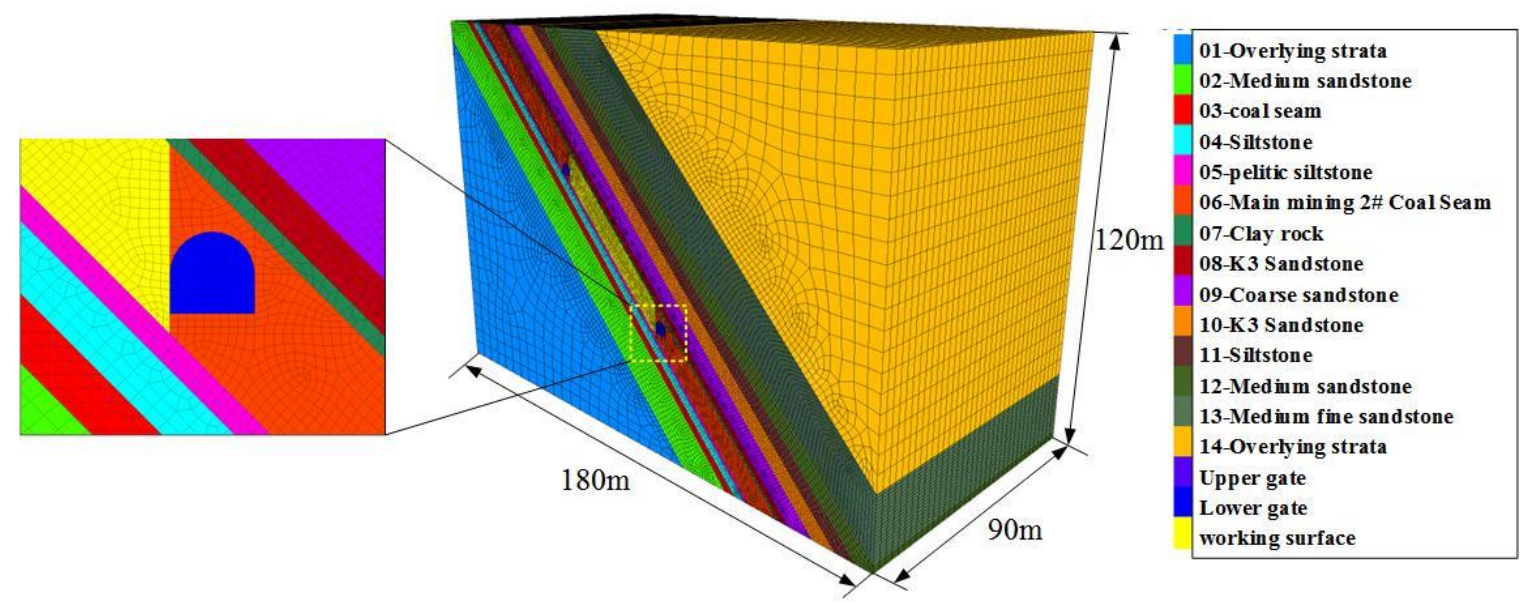

Fig3. 3D numerical calculation model 
Study on the Instability Mechanism of Large Dip Roadway in the Coal Seam

Table1. Physical and mechanical parameters of coal and rock in this simulation

\begin{tabular}{|l|l|l|l|l|l|l|}
\hline $\begin{array}{l}\text { Name of rock } \\
\text { stratum }\end{array}$ & $\begin{array}{l}\text { density } \\
\left(\mathbf{k g} / \mathbf{m}^{\mathbf{3}}\right)\end{array}$ & $\begin{array}{l}\text { Elastic } \\
\text { modulus } \\
(\mathbf{G P a})\end{array}$ & $\begin{array}{l}\text { Poisson's } \\
\text { ratio }\end{array}$ & $\begin{array}{l}\text { Cohesion } \\
(\mathbf{M P a})\end{array}$ & $\begin{array}{l}\text { Internal friction } \\
\text { angle }\left(^{\circ}\right)\end{array}$ & $\begin{array}{l}\text { Tensile } \\
\text { strength } \\
(\mathbf{M P a})\end{array}$ \\
\hline $\begin{array}{l}\text { Overlying } \\
\text { strata }\end{array}$ & 2500 & 3 & 0.21 & 2.3 & 34 & 2.6 \\
\hline $\begin{array}{l}\text { Medium } \\
\text { sandstone }\end{array}$ & 2680 & 3.9 & 0.18 & 3.3 & 35 & 2.9 \\
\hline Siltstone & 2690 & 2.2 & 0.22 & 1.2 & 33 & 1.4 \\
\hline Coal seam & 1400 & 1 & 0.3 & 0.2 & 25 & 0.3 \\
\hline $\begin{array}{l}\text { Pelitic } \\
\text { siltstone }\end{array}$ & 2090 & 1.2 & 0.27 & 0.8 & 28 & 0.5 \\
\hline Clay rock & 1800 & 0.9 & 0.29 & 0.6 & 26 & 0.6 \\
\hline $\begin{array}{l}\text { Coarse } \\
\text { sandstone }\end{array}$ & 2400 & 1.4 & 0.22 & 1.2 & 31 & 1.2 \\
\hline $\begin{array}{l}\text { K3 } \\
\text { Sandstone }\end{array}$ & 2200 & 1 & 0.23 & 2.1 & 32 & 2.8 \\
\hline $\begin{array}{l}\text { Medium fine } \\
\text { sandstone }\end{array}$ & 2560 & 2.1 & 0.31 & 2.2 & 33 & 2.1 \\
\hline
\end{tabular}

\subsection{Numerical Simulation Scheme}

In order to make a comparative study of the influence of coal seam inclination on the instability mechanism of roadway in high-dip coal seam under the circumstances of roof with and without weak surface, the following simulation scheme is designed: In the case of roof with weak surface and without weak surface, the evolution law of surrounding rock displacement, weak surface shear displacement and plastic zone under coal seam dip angle of $0^{\circ}, 10^{\circ}, 20^{\circ}, 30^{\circ}$ and $45^{\circ}$ are studied.

\subsection{Weak Surface Shear Displacement Monitoring Scheme}

In order to facilitate the study of the influence of coal seam inclination on the weak surface shear deformation of roadway roof, 10 monitoring points are arranged at the weak surface of coal-clay rock directly above the roadway roof to monitor the shear slip state of the weak surface under different inclinations. The specific layout of the measuring points is shown in Fig. 4.

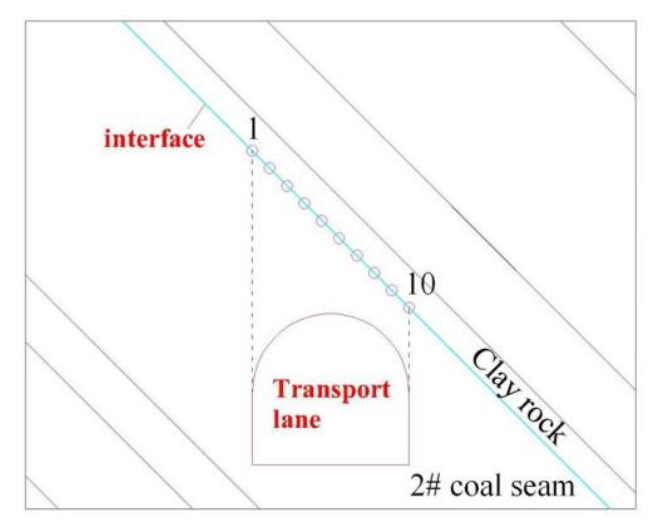

Fig4. Schematic diagram on monitoring points distribution on the shear displacement of weak surface

\section{ANALYSiS OF NUMERICAL RESULTS}

\subsection{Influence of Coal Seam Dip Angle on Weak Surface Shear Displacement}

Fig. 5 shows the distribution cloud map of shear displacement on the weak surface at different dip angles, and the variation of shear displacement at different monitoring points with the dip angle is shown in Fig. 6. It can be seen from the figure that:

(1) The variation of shear displacement on weak surface presents obvious inclination effect. At the angle of $0^{\circ}$, the shear displacements at each measuring point are distributed approximately symmetrically along the central axis of the roadway, and the shear displacements at the central axis are 0 ; At the dip angle of $10^{\circ} \sim 45^{\circ}$, as the monitoring points gradually moved from the left side of the roadway to the right side, the shear displacement on the weak surface showed a trend of first increasing and then decreasing, which was mainly related to the degree of roof movement toward the 
facing surface of the roadway after roadway excavation and unloading; It should be noted that although the shear displacement on the weak surface near the monitoring point on the right side of the middle line of the roadway at the dip angles of $10^{\circ}$ and $20^{\circ}$ decreases first and then increases, it has little influence on the overall trend of the curve, so it will not be studied here.

(2) The maximum shear displacement and its position on the weak surface are significantly affected by the dip angle. In addition to the $0^{\circ}$ dip angle, with the gradual increase of the dip angle, the maximum shear displacement position gradually moves from the left side to the right side of the middle line of the roadway, which may have a certain influence on the roadway instability mode; The maximum shear displacement presents a nonlinear increase trend with the increase of inclination angle, but the increase rate gradually decreases. For example, when the inclination angle increases from $0^{\circ}$ to $10^{\circ}$, its maximum shear displacement increases by $135 \mathrm{~mm}$ and $72.58 \%$, while when the inclination angle increases from $10^{\circ}$ to $20^{\circ}$, its maximum shear displacement increases by only $33 \mathrm{~mm}$ and $10.28 \%$. This indicates that the sensitivity of shear deformation on the weak surface of roadway roof with large dip angle to the effect of rock dip angle is gradually reduced, which has certain guiding significance for the design of shear performance of roadway support structure with large dip angle.

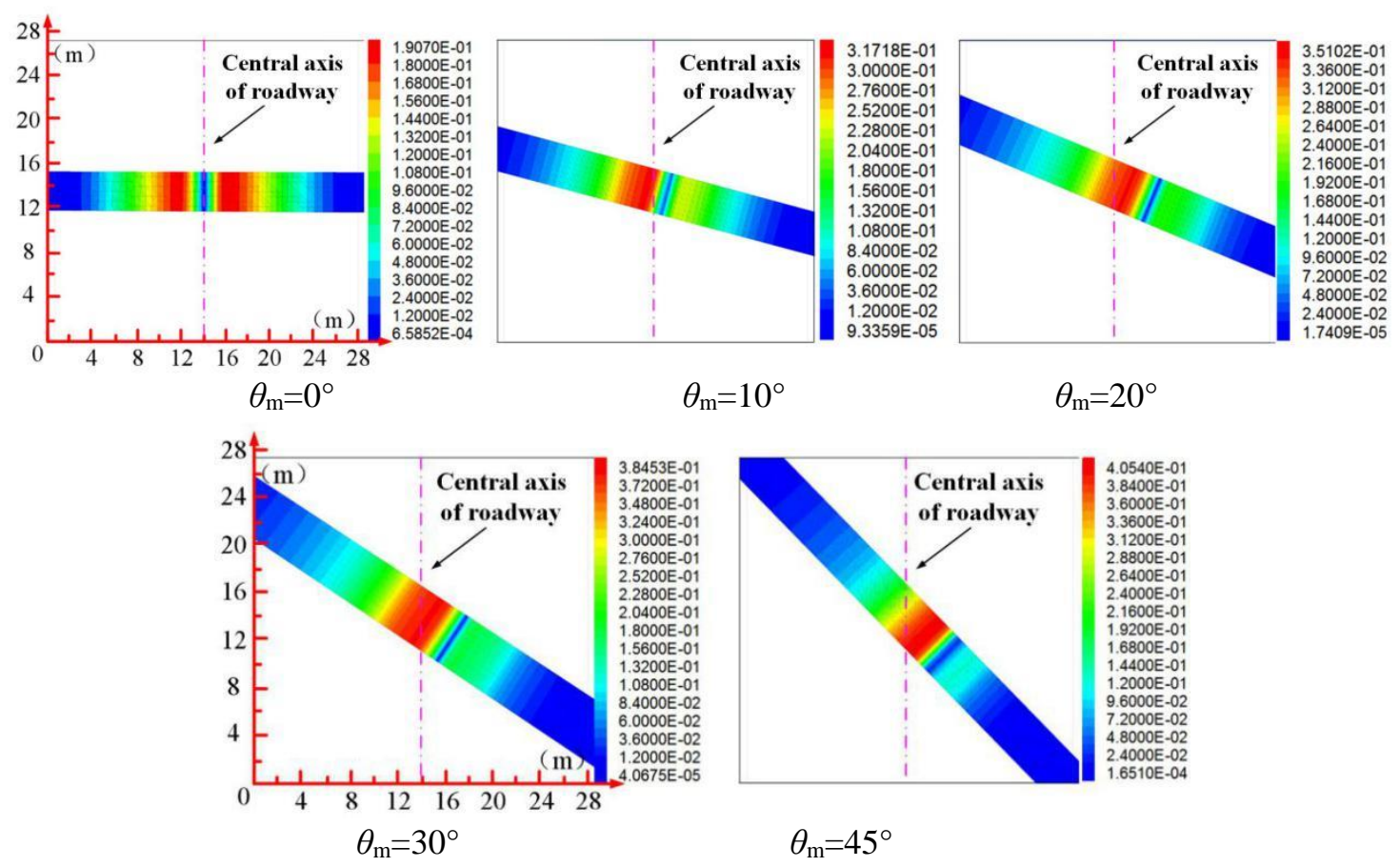

Fig5. Shear displacement cloud image of weak surface at different inclinations

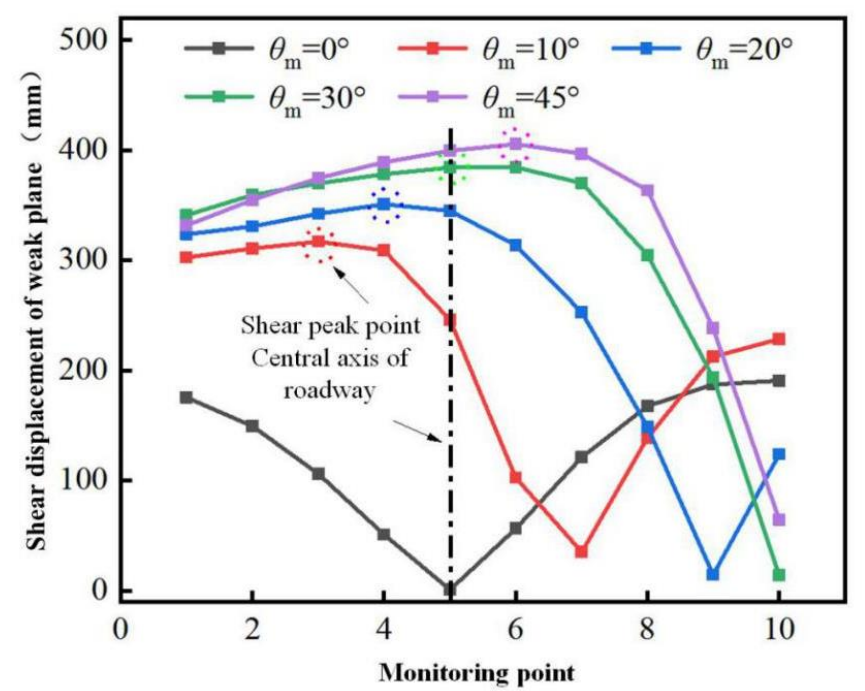

(a) Shear displacement curve of weak surface with monitoring point 


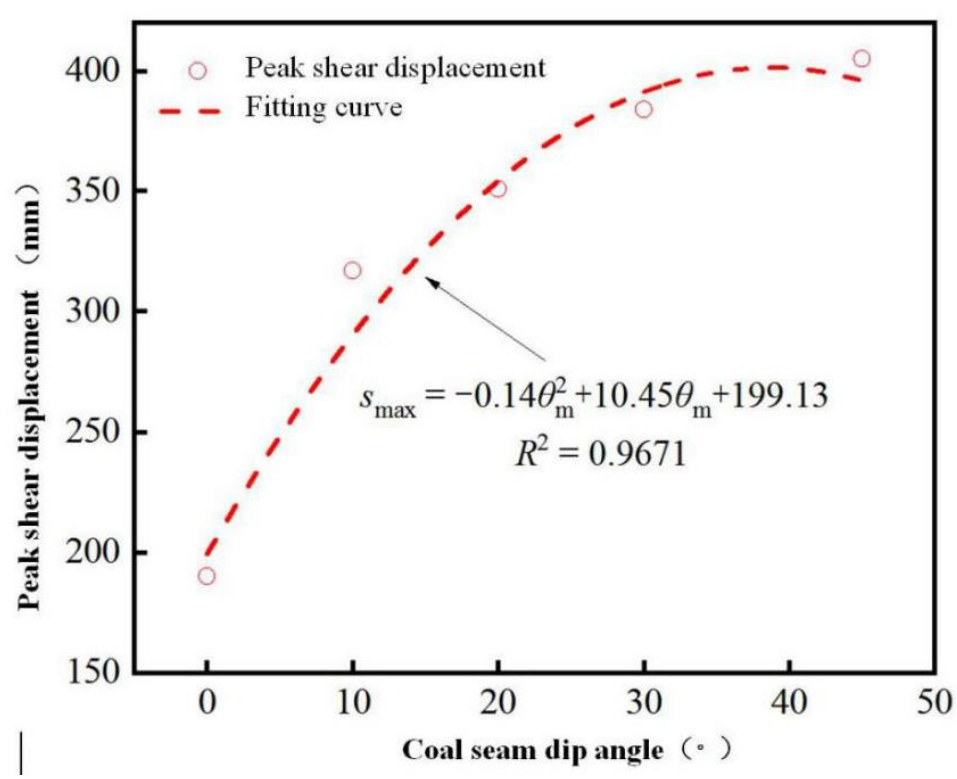

(b) Curve of peak shear displacement with dip angle

Fig6. Shear displacement of weak surface varies with the inclination angle

\subsection{The Influence of Coal Seam Dip Angle on the Displacement Field Evolution of Roadway Surrounding Rock}

(1) Displacement field distribution of surrounding rock of roadway without considering the influence of weak surface

Fig. 7 shows the total displacement cloud map of surrounding rock at different dip angles ignoring the influence of the weak surface. The convergence of roadway section after deformation is shown in Fig. 8. Fig. 9 shows the change curve of total displacement with the position of roadway surface. It can be seen from the figure that:

(1) At the inclination angle of $0^{\circ}$, the overall roadway deformation presents an approximately symmetric distribution feature, and meets the variation trend of roof > side > floor. The above analysis shows that for the straight wall arch roadway near the horizontal coal seam, the roof and top of the side should be the key reinforcement area.

(2) Under the dip angle of $10^{\circ} \sim 45^{\circ}$, the overall deformation of the roadway presents obvious asymmetric distribution characteristics, and the deformation evolution law also changes gradually with the increase of the dip angle. With the increase of the dip angle, the deformation of the left side of the roadway always maintains a single deformation mode, that is the top > the bottom, and the deformation of the left side of the roadway is larger than that of the $0^{\circ}$ dip angle; The deformation of roadway roof and floor increased significantly with the increase of inclination angle, and the deformation of roof always presented the characteristics of left arch shoulder > right arch shoulder. The maximum deformation was always located in the area of left arch shoulder, and gradually shifted from the lower part of left arch shoulder to the upper part; The deformation of the right side of roadway changes little with the increase of the dip angle, and the maximum deformation gradually shifts from the top to the bottom; On the whole, under the dip angle of $10^{\circ} \sim 30^{\circ}$, the maximum deformation of the roadway presents the variation trend of the left side $>$ roof $>$ floor $>$ right side, while under the dip angle of $45^{\circ}$, the deformation presents the variation trend of the floor $>$ the roof and the left side > the right side, but the maximum deformation of the bottom side, the left side and the top side are relatively close.

In analysis, when no weak surface effect, the obliquity effect on the overall deformation of roadway and deformation pattern are important influence, with the increase of angle, present the obviously asymmetric introvert type of roadway deformation characteristics, the deformation difference of each part is significant, in which deformation of left side is larger, but lower sensitivity to obliquity effect, roof and floor deformation increase significantly, the obliquity effect sensitivity is higher, so for the large dip angle of coal seam roadway, left side, roof and floor of roadway should focus on strengthening regional. 


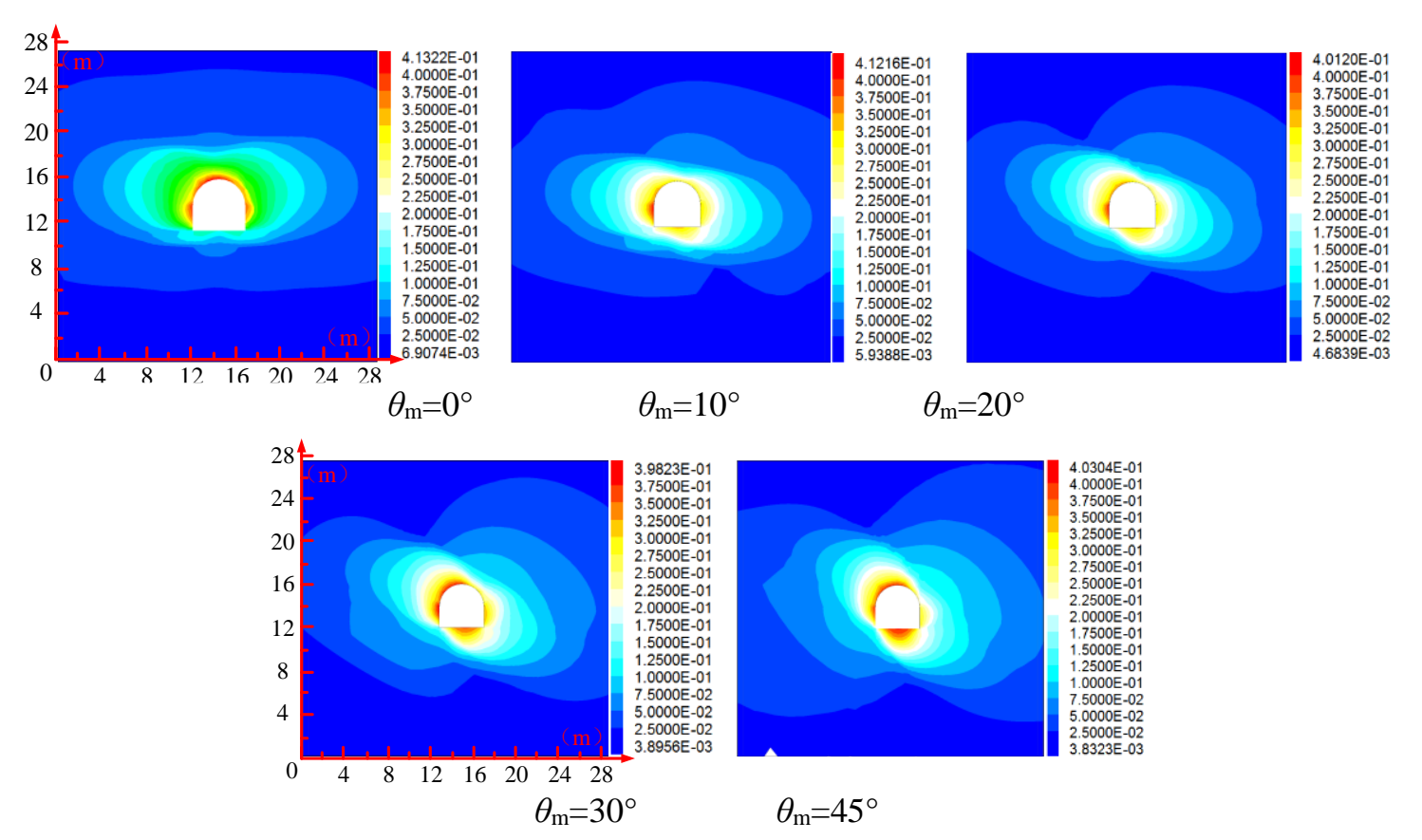

Fig7. Total displacement cloud map of surrounding rock at different inclination angles ignoring the effect of weak surface

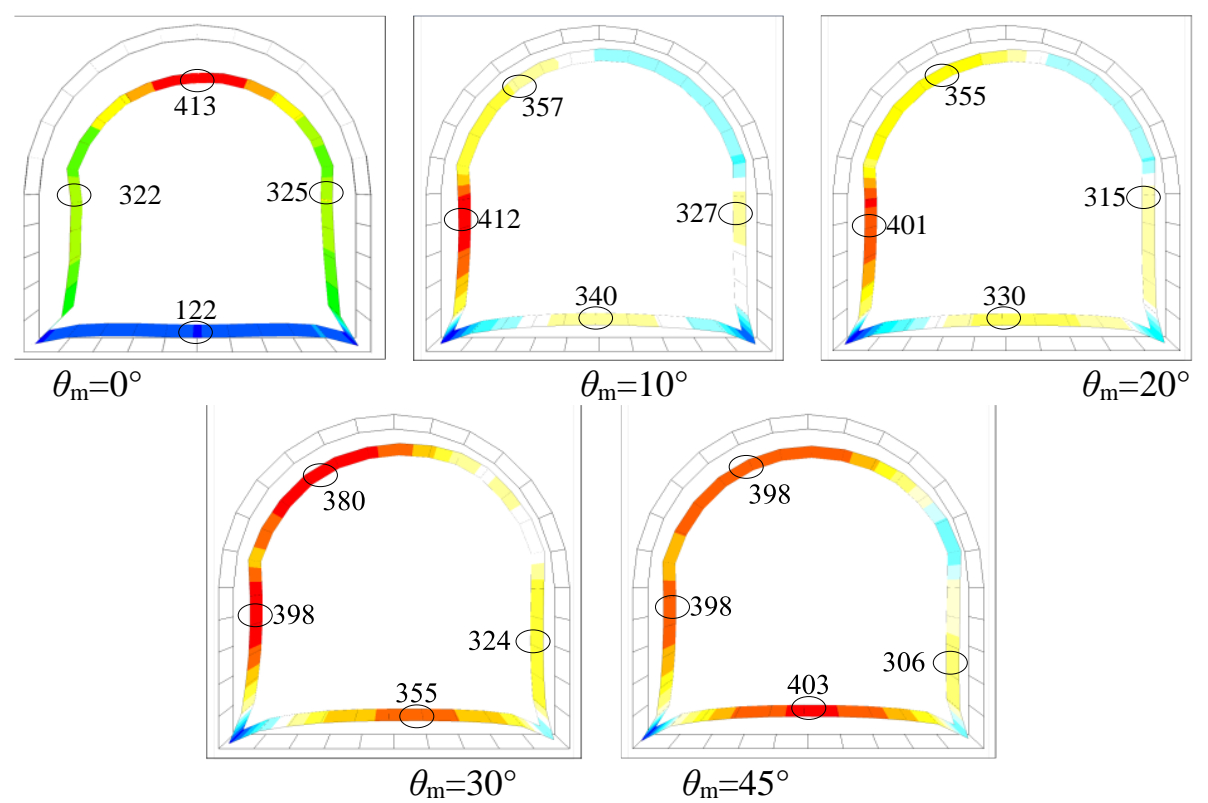

Fig8. Schematic diagram on convergent deformation of surrounding rock at different inclination angles ignoring the effect of weak surface

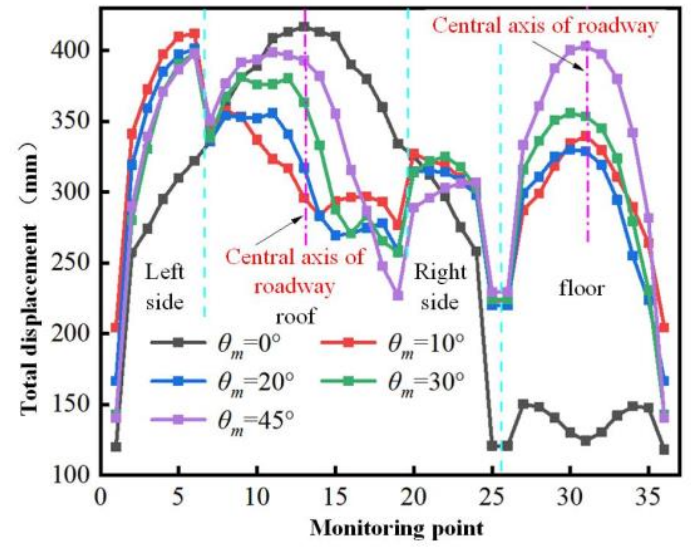

Fig9. Total displacement of surrounding rock varies with the roadway surface position at different inclination angles ignoring the effect of the weak surface 
(2) Distribution of roadway surrounding rock displacement field considering weak surface slip effect Fig.10 shows the total displacement cloud map of surrounding rock at different dip angles considering the influence of the weak surface, and the convergence of roadway section after deformation is shown in Fig. 11.Fig. 12 shows the change curve of total displacement with the position of roadway surface. The following rules can be summarized from the above figure:

(1) At the inclination angle of $0^{\circ}$, the overall deformation of the roadway presents an approximately symmetric distribution along the middle line, and meets the changing trend of roof > side > floor, which is basically consistent with the case without weak surface, but the value is significantly greater than that of the latter.

(2) At the dip angle of $10^{\circ} \sim 45^{\circ}$, the overall deformation of the roadway presents obvious asymmetric distribution characteristics, but the deformation pattern is less affected by the dip angle. With the increase of the dip angle, the deformation of the left side of the roadway always presents the variation trend of the top > the side, but the overall variation is small; The deformation of roadway roof and floor increased significantly with the increase of inclination angle, and the deformation of roof presented the characteristics of right arch shoulder > left arch shoulder. The maximum deformation was always located in the area of right arch shoulder, and gradually shifted from higher part of the right arch shoulder to the lower part with the increase of inclination angle; With the increase of the dip angle, the maximum deformation of the right side of the roadway gradually shifted from the top to the bottom, but the maximum deformation changed little. On the whole, under the dip angle of $10^{\circ} \sim 45^{\circ}$, the maximum deformation of the roadway presents the variation trend of the roof $>$ left side > floor and right side, and the deformation difference of each part is relatively significant.

(3) No matter what the dip angle is, the weak surface slip effect has a significant influence on the deformation of surrounding rock. Compared with the condition without weak surface, the overall deformation of surrounding rock of the roadway increases significantly at $0^{\circ}$ dip angle, but the deformation mode still presents the changing characteristics of roof $>$ side $>$ floor, indicating that the deformation degree of the roadway at $0^{\circ}$ dip angle is significantly affected by the sliding effect of the weak surface, but the deformation mode is basically independent of the dip angle; Under the dip angle of $10^{\circ} \sim 45^{\circ}$, the overall deformation of surrounding rock also presents a significant increase trend, compared with the slope angle of the $45^{\circ}$ coal seam without the weak surface, when considering the influence of the weak surface, the roadway deformation mode is transformed from the bottom $>$ roof and the left side > the right side to the roof > the left side> the floor and the right side. It is shown that the weak surface slip effect has an important influence on the deformation degree and deformation mode of large dip roadway.

To sum up, when considering the influence of weak surface, the effect of coal seam dip angle can have an important influence on the deformation characteristics of roadway, especially under the condition of large dip angle, which has the most significant influence on the deformation of roadway roof and floor, so it should be the key reinforcement area.

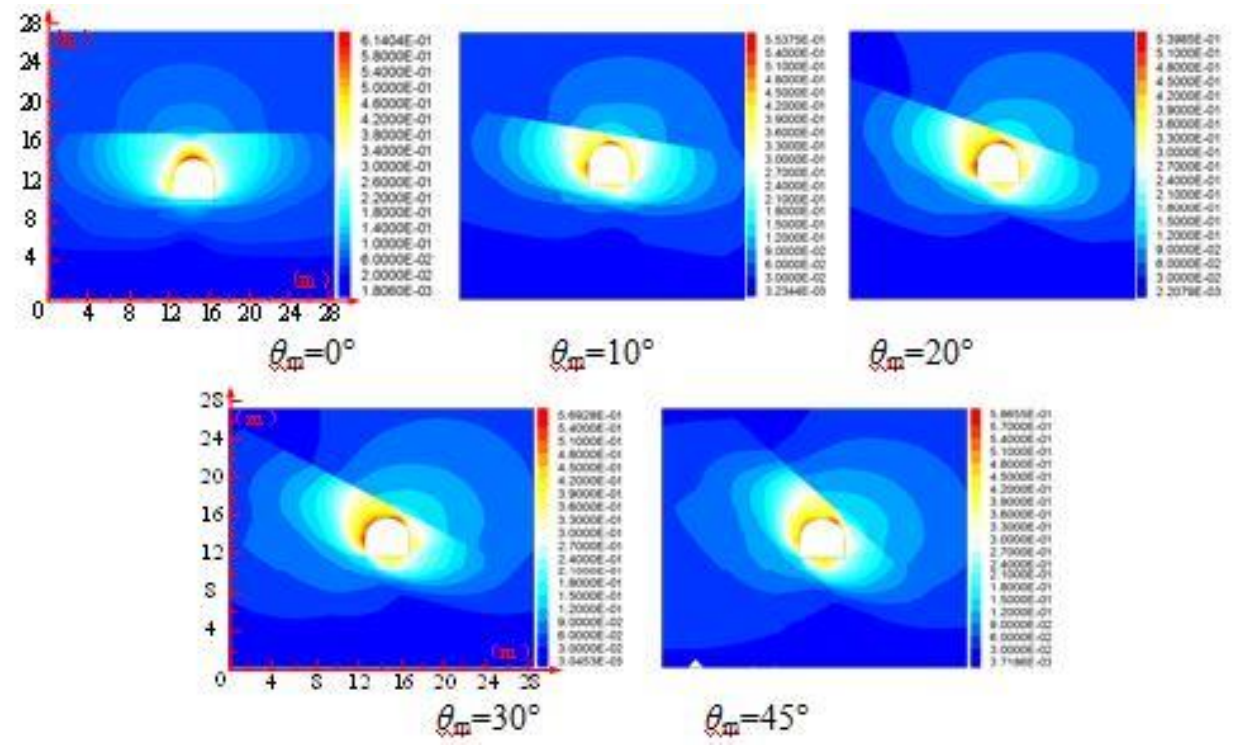

Fig10. Total displacement cloud map of surrounding rock at different inclination angles considering the effect of weak surface 

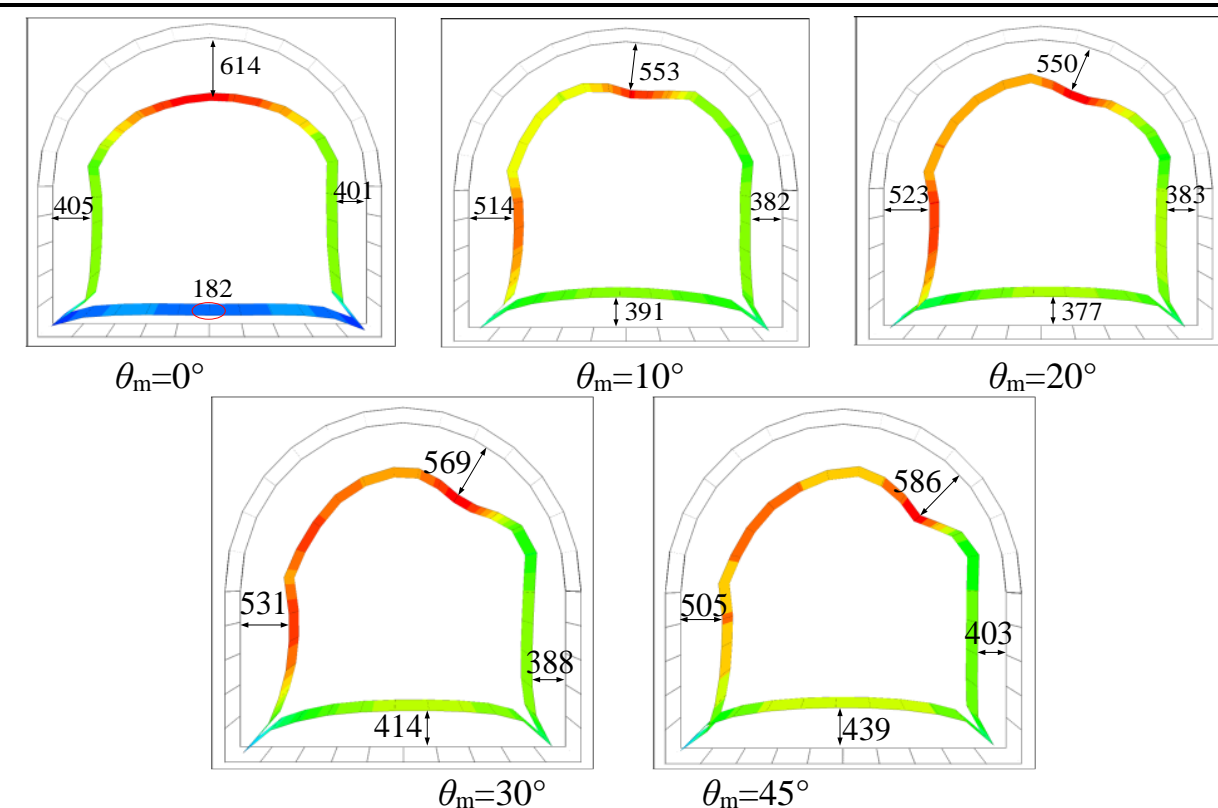

Fig11. Schematic diagram on convergent deformation of surrounding rock at different inclination angles considering the effect of weak surface

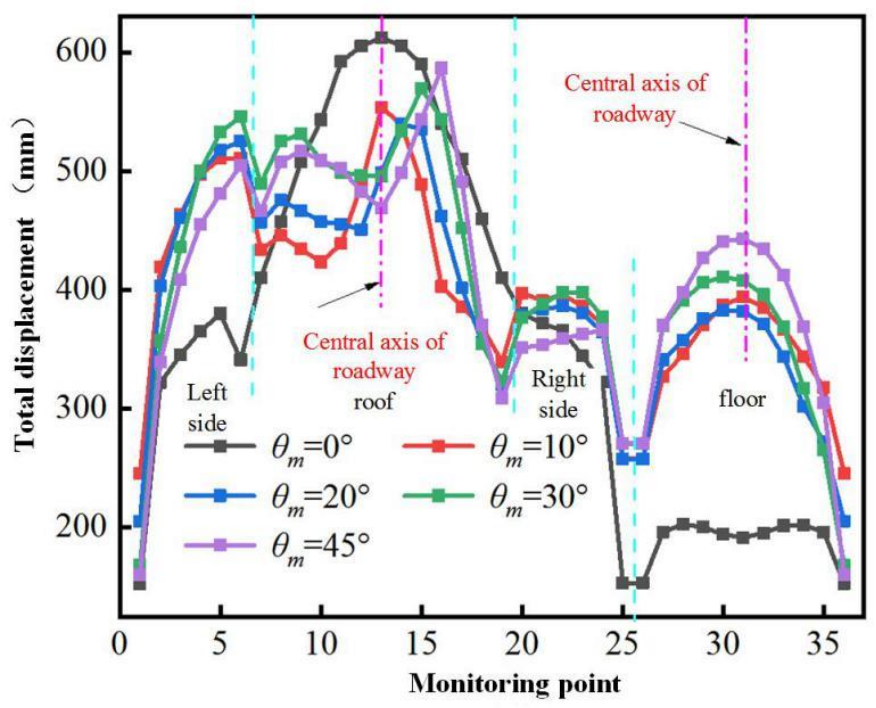

Fig12. Total displacement of surrounding rock varies with the roadway surface position considering the effect of weak surface

\subsection{The Influence of Coal Seam Dip Angle on the Evolution Law of Surrounding Rock Plastic}

\section{Zone}

(1) The distribution of plastic zone of surrounding rock in roadway ignoring the influence of weak surface

Fig. 13 presents the cloud map of the plastic zone of surrounding rock in roadway at different dip angles without considering the influence of the weak surface. The following rules can be summarized from the figure:

The distribution of plastic zone presents obvious inclination effect. At the dip angle of $0^{\circ}$, the plastic zone of surrounding rock is distributed symmetrically along the middle line, and the plastic zone range of the roof is obviously larger than that of the floor, the plastic zone extends mainly in the direction perpendicular to the roof, the two sides and the floor. At the dip angle of $10^{\circ} \sim 45^{\circ}$, with the increase of the dip angle, the plastic zone distribution pattern changes significantly, mainly reflected in the following three aspects:(1)The plastic zone in the vertical direction of the roof gradually drops from the K3 sandstone layer to the clay rock layer, and its spreading direction transforms from the 
vertical roof direction to the top of the rock trend; (2)The plastic zone of two sides of roadway gradually shifted from top position to floor direction; (3) The plastic zone of floor is gradually reduced from middle sand to siltstone, and its spreading direction gradually shifts from the vertical floor direction to the lower part of the rock stratum dip.

To sum up, the additional shear stress caused by rock slope effect can effectively change the distribution form of surrounding rock plastic zone and transform it from symmetrical mode to asymmetric shear-slip mode. The distribution feature can accelerate the shear failure trend of surrounding rock of roadway, and make it show the characteristics of asymmetric shear instability, especially under the condition of large dip angle, the instability feature is more obvious.
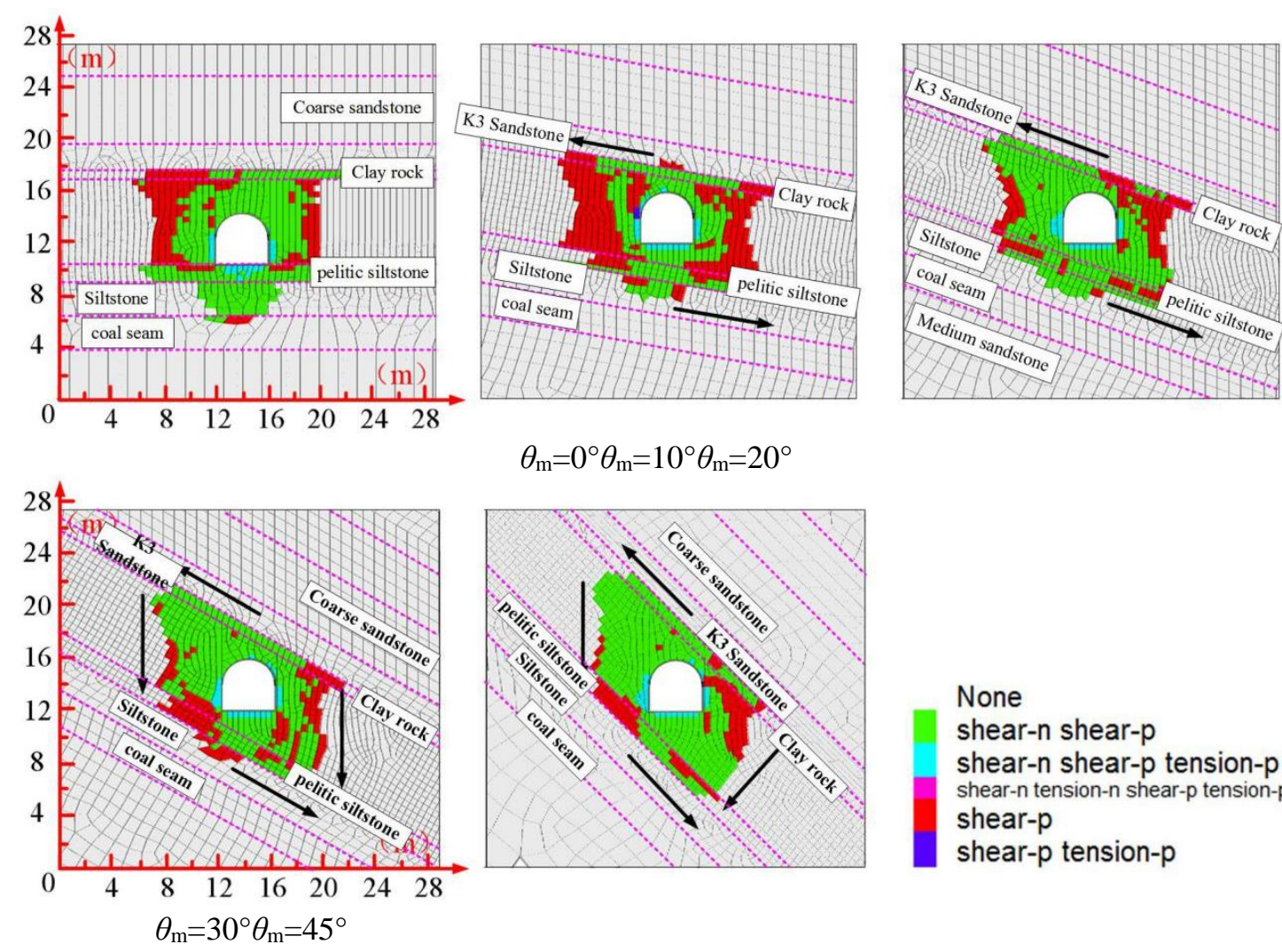

$$
\theta_{\mathrm{m}}=0^{\circ} \theta_{\mathrm{m}}=10^{\circ} \theta_{\mathrm{m}}=20^{\circ}
$$

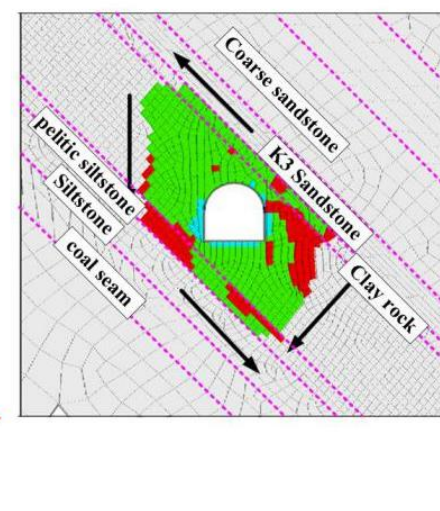

\section{None}

shear-n shear-p

shear-n shear-p tension- $p$

shear- $n$ tension- $n$ shear- $p$ tension- $p$ shear-p

shear-p tension-p

Fig13. Plastic zone cloud map of surrounding rock at different inclination angles ignoring the effect of weak surface

(2) The distribution of plastic zone of surrounding rock in roadway considering the weak surface slip effect

Fig. 14 shows the distribution cloud map of the plastic zone of surrounding rock at different dip angles considering the weak surface slip effect. It can be seen from the figure that:

(1) At $0^{\circ}$ dip angle, the plastic zone form of surrounding rock of roadway is approximately symmetrical distribution. The plastic zone mainly extends along the direction perpendicular to the roof, the two sides and the floor. At the dip angle of $10^{\circ} \sim 30^{\circ}$, the plastic zone of the roof gradually penetrates to the coarse sandstone layer, the plastic zone of floor gradually penetrates to the unworkable coal seam, and the plastic zone of both sides gradually expands to the strata tendency compared with the $0^{\circ}$ dip angle; At an inclination angle of $45^{\circ}$, the plastic zone of the roof is gradually reduced from coarse sandstone to $\mathrm{K} 3$ sandstone. The plastic zone of floor is gradually reduced from unworkable coal seams to siltstone strata, the contour of the plastic zone on the left side presents obvious shear slip along the trend of coal seam. The results show that the larger the slip degree of the weak surface is, the more obvious the inhibition effect of the weak surface on the expansion of the plastic zone of the roof to the deep and accelerate its extension along the weak surface.

(2) No matter at what dip angle, the roadway surrounding rock surface presents obvious tensile failure mode, the deep surrounding rock presents shear failure mode. With the increase of dip angle, the 
distribution pattern of shear failure unit of surrounding rock of roadway shows the feature of transferring from left side to right side of floor, it shows that the failure degree of roadway floor increases significantly under the condition of large dip angle coal seam.

(3) Compared with the situation without the influence of weak surface, the plastic zone of surrounding rock of roadway presents an overall increasing trend, especially in the roof and bottom plate increase most significantly, for example, when the inclination is $10^{\circ}$, the depth of the plastic zone on the roof, floor, left side and right side of the roadway increased by $2.77 \mathrm{~m}, 1.84 \mathrm{~m}, 1.23 \mathrm{~m}$ and $1.25 \mathrm{~m}$ respectively, increases of $100 \%, 40 \%, 19 \%$ and $25.46 \%$. This is mainly because, compared with the case without the weak surface, the additional stress caused by the sliding effect of the weak surface can intensify the stress concentration degree of roadway roof and accelerate the gradual transfer of plastic zone to the deep of roadway.
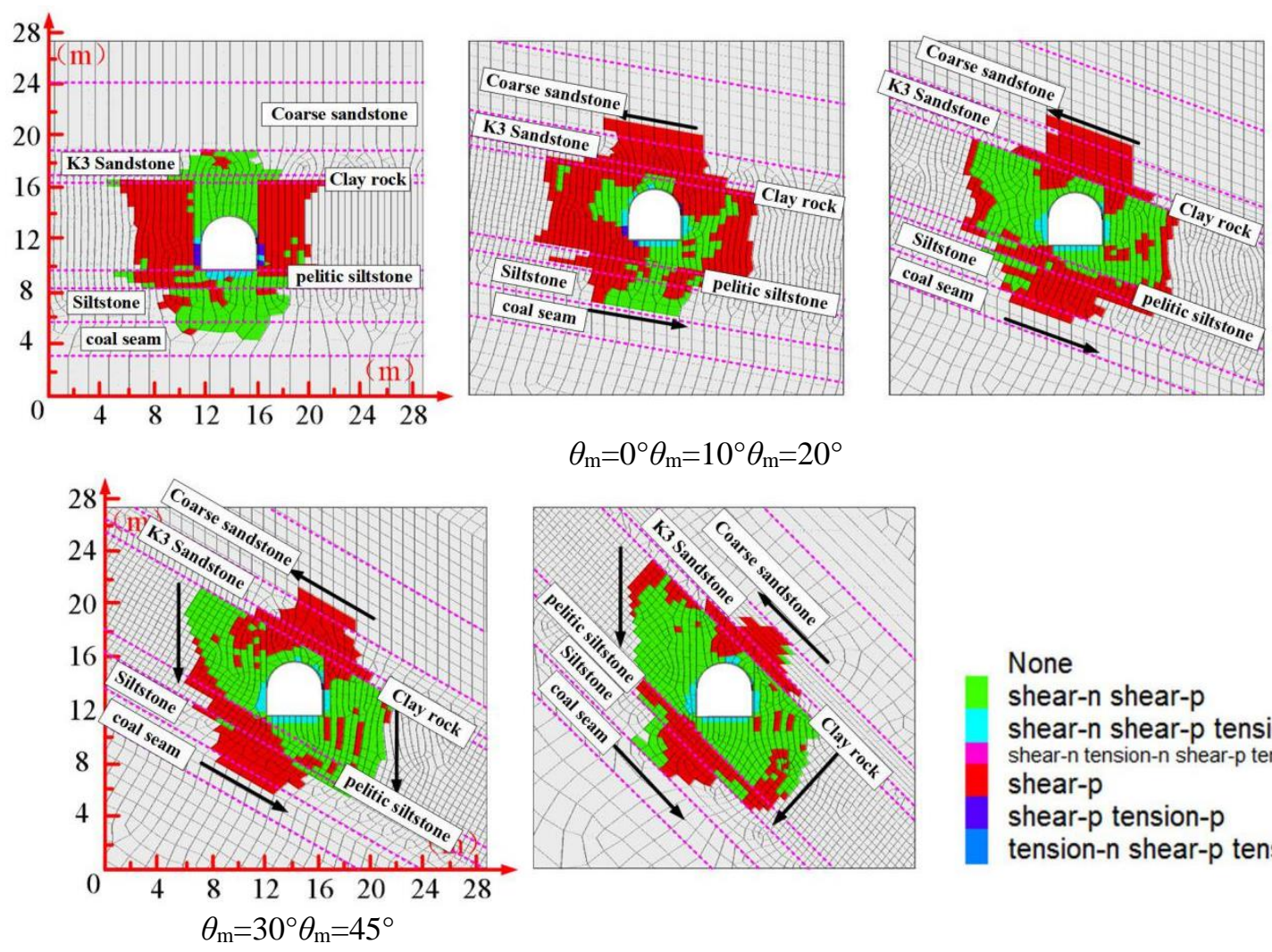

$$
\theta_{\mathrm{m}}=0^{\circ} \theta_{\mathrm{m}}=10^{\circ} \theta_{\mathrm{m}}=20^{\circ}
$$

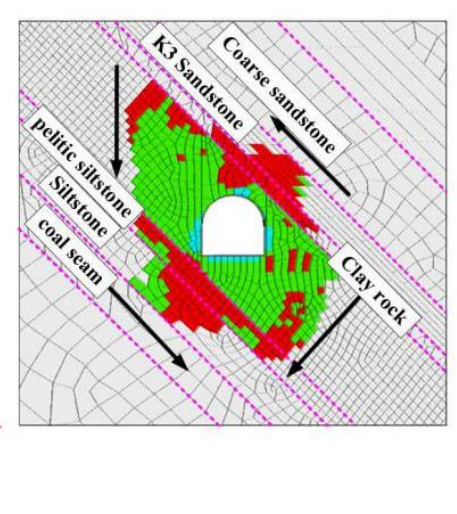

\section{None}

shear-n shear-p

shear-n shear- $p$ tension- $p$

shear- $n$ tension- $n$ shear-p tension- $p$

shear-p

shear-p tension- $p$

tension-n shear-p tension-p

Fig14. Plastic zone cloud map of surrounding rock at different inclination angles considering the effect of weak surface

\section{CONCLUSION}

In this paper, based on the engineering background of a large-dip coal seam transport roadway in a certain mine, FLAC3D simulation software is used to compare and study the evolution law of the shear displacement, total displacement and plastic zone of coal-clay rock on the weak surface of a large-dip coal seam roadway when the coal seam inclination is $0^{\circ} \sim 45^{\circ}$, considering the weak surface and non-weak surface of the roof. The main conclusions are summarized as follows:

(1) The influence of dip angle on the failure mode of roadway surrounding rock is closely related to whether the weak surface slip effect is considered; The maximum shear displacement and its position on the weak surface are significantly affected by the dip angle, and the dip angle effect is obvious; The maximum shear displacement presents a nonlinear increase trend with the increase of the dip angle, but the increase rate gradually decreases, and the sensitivity of the shear deformation on the weak surface of the roadway roof under large dip angle to the effect of the dip angle gradually decreases.

(2) When there is no weak surface, the maximum deformation of roadway changes from left side $>$ roof $>$ floor $>$ right side under the angle of $10^{\circ} \sim 30^{\circ}$ to floor $>$ roof or left side > right side under $45^{\circ}$ inclination angle, and the roof deformation always presents the distribution characteristics of left 
spandrel > right spandrel; With the increase of dip angle, the expansion trend of plastic zone extends from horizontal and vertical direction to coal rock tendency.

(3) When considering the weak surface effect, the maximum deformation of roadway at any dip angle presents the variation characteristics of the roof $>$ left side $>$ floor or right side, and the deformation of the roof is dominated by the right arch shoulder. The plastic zone expansion trend is basically the same as that without the weak surface, but the range is larger than the former.

(4) In practical engineering, when there is a weak surface in the roof of a roadway with large dip angle, it is necessary to strengthen the control of the weak surface in surrounding rock of the roadway, so as to prevent the overall shear instability of the roadway caused by shear slip on the weak surface. The dip angle effect of coal seam can have an important influence on the deformation characteristics of roadway, especially the most significant influence on the deformation of roadway roof and floor under the condition of large dip angle, which should be the key reinforcement area; When there is no weak surface influence, the left side, roof and floor of roadway should be key reinforcement areas for roadway with large dip angle. The distribution of plastic zone in surrounding rock is transformed from symmetrical mode to asymmetric shear-slip mode, which accelerates the shear failure trend of roadway surrounding rock, so attention should be paid to it.

\section{REFERENCES}

[1] Guo H, Yuan L, Shen B, et al. Mining-induced strata stress changes, fractures and gas flow dynamics in multi-seam longwall mining[J]. International Journal of Rock Mechanics \& Mining Sciences, 2012, 54: 129-139.

[2] Yun D F, Xin Y J, Ji H Y, et al. Roof monitoring and support design of roadway in large dip angle "Three Soft" outburst coal seam[J]. Journal of Xi'an University of science and technology, 2010(03):260-265.

[3] Zhang M. Mechanical analysis and support technology of surrounding rock instability of roadway with large dip angle and thin roof[D]. China University of mining and technology, 2014.

[4] Yang K, Xie G X. Unsymmetrical bolt mesh cable support and practice in large inclined seam[J]. Journal of underground space and Engineering, 2013, 9(4):924-927.

[5] Shen B. Coal Mine Roadway Stability in Soft Rock: A Case Study[J]. Rock Mechanics \& Rock Engineering, 2014, 47(6):2225-2238.

[6] Sun X, Wang D, Feng J, et al. Deformation control of asymmetric floor heave in a deep rock roadway: A case study[J]. International Journal of Mining Science and Technology, 2014, 24(6):799-804.

[7] Yang S Q, Chen M, Jing H W, et al. A case study on large deformation failure mechanism of deep soft rock roadway in Xin'An coal mine, China[J]. Engineering Geology, 2017, 217:89-101.

[8] Cao S G, Dou L M. Finite element analysis of mechanical deformation of roadway with large dip angle[J]. Journal of mining and safety engineering, 1999(3).

[9] Liu D F. Roof support technology of roadway in high pressure and large angle loose coal seam under water erosion condition[C]. New theory and technology of coal mining-Collection of papers of 2006 academic annual meeting of Mining Professional Committee of China Coal Society. 2006.

[10] Chai J, Du W G, Zhang D D, et al. Study on roof movement law of large angle coal seam based on BOTDA Technology[J]. Journal of rock mechanics and Engineering, 2019, 38(9):1809-1818.

[11] Dai X F, Wang J C. Study on deformation failure mechanism and support of roadway surrounding rock in large inclined seam[J]. Shanxi Coking Coal Technology, 2018, 274 (06):22-26.

[12] Niu S Q, Yang S S, Li Y, et al. Shear instability mechanism and support method of large span roadway roof [J]. Journal of coal industry, 2014, 39(S2):325-331.

[13] Xin Y J, Gou P F, Fu D F, et al. Instability characteristics and support analysis of surrounding rock in soft rock roadway with large dip angle[J]. Journal of mining and safety engineering, 2012,29(5):637-643.

[14] Gou P F, Xin Y J. Stability analysis of roof structure of mining roadway in large inclined seam[J]. Journal of coal industry, (10):1607-1611.

[15] Li H W, Sun F Z, Guan W M, et al. Numerical simulation of deformation and failure characteristics of roadway surrounding rock in large inclined thick coal seam[J]. Coal technology, 034(10):70-72.

[16] Li D. Failure mechanism and bolt support analysis of mining roadway in large inclined seam[D]. Xi'an University of science and technology, 2005.

[17] Zhang H. Instability mechanism and engineering application of upper side coal mass in mining roadway driving along roof in inclined coal seam[D]. Henan University of Technology, 2009.

[18] Guo D M, Li T, Wu S, et al. Failure mechanism of surrounding rock and optimization of supporting parameters in large inclined and extremely soft thick coal roadway[J]. Journal of Henan University of Technology (NATURAL SCIENCE EDITION), 2014,33(5):569-575. 
[19] Fan M J, Kang H P, Lin J, et al. Study on comprehensive control technology of surrounding rock of roadway with large dip angle and buried depth of $1300 \mathrm{~m}[\mathrm{~J}]$. Journal of mining and safety engineering, 2015,32 (5): 706-713.

[20] M.Y. Fisekci, A. Chrzanowski, B.M. Das. Subsidence studies in thick and steep coal seam mining: Proc 1st Conference on Ground Control in Mining, Morgantown, 27-29 July 1981, P230-238. Publ Morgantown: West Virginia University, 1981[J]. 20(1):0-0.

[21] Mrig G.C, Sinha A.N. Proposing a new method for thick, steep and gassy XV seam of Sudamdih. International symposium on thick seam mining[M]: problem and issues (ISTS'92), 1992: 445-456.

[22] Zhang B, Cao S. Study on first caving fracture mechanism of overlying roof rock in steep thick coal seam[J]. International Journal of Mining Science and Technology, 2015, 25(1):133-138.

[23] Proyavkin E.T. New nontraditional technology of working thin and steep coal seams[J]. UgolUkrainy. 1993,(3):2-4.

[24] Y.P. Wu, P.S. Xie, H.W. Wang. Theory and Practices of Fully Mechanized Longwall Mining in Steeply Dipping Coal Seam [J]. Mining Engineering, 2013, 65(1): 35-41.

[25] Y.P. Wu, H.W. Wang, P.S. Xie and Y.J. Yu. Stress Evolution and Instability Mechanism of Overlying Rock in Steeply Dipping seam Mining [C]. 2013 Word Mining Congress (WMC), August 11-15, 2013. Montreal, Canada.

[26] Yun D F, Liu Z, Su P Z, et al. Safe reset of toppling support in large inclined angle unstable soft coal fully mechanized caving face[J]. China Mining, 2016, 25(001):131-134.

[27] Tao L J, Wang Y J. Movement and failure of overlying strata in large inclined seam[J]. Journal of coal industry, 1996,21(06):23-26.

[28] Zhao Y F, Zhang X Y, Tu M. Roof caving characteristics and ground pressure behavior law in mining of large inclined seam[J]. Journal of mining and safety engineering, 2007, 24(02):109-112.

[29] Hua D Y. Analysis on stability and failure of floor in large inclined seam[C]. Conference on rock mechanics and support, 1996.

[30] Wang Jinan, Jiao Junling. Criteria of support stability in mining of steeply inclined thick coal seam[J]. International Journal of Rock Mechanics \& Mining Sciences, 2016, (82):22-35.

[31] Lv X J, Geng M H, Hao B B. Study on the influence of large dip angle on caving law under complex conditions[J]. Journal of Hebei University of Technology (NATURAL SCIENCE EDITION), 2007(04):93-95.

[32] Wu Y P, Yun D F, Xie P S, et al. Long wall fully mechanized coal mining in steep seam: progress, practice and scientific problems[J]. Journal of coal industry, 2020, 45(01):24-34.

[33] Du Ji-ping, Meng Xian-rui. Mining science[M]. Xuzhou: China university of mining \& technology publishing house, 2009. "In Chinese".

[34] Yong Y, Shihao T, Qi W, et al. Mechanics of rib spalling of high coal walls under fully mechanized mining[J]. Mining Science and Technology(china),2011,21(1): 129-133.

[35] Adams G.D, Jager A.J. Petroscopic observations of rock fracturing ahead of stope faces in deep-level gold mines [J]. Journal of the South African Institute of Mining and Metallurgy, 1980,80(6):204-209. 


\section{AUTHORS' BIOGRAPHY}

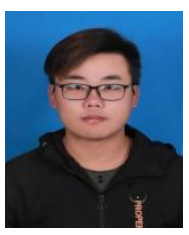

Zhiwei Feng, is currently studying for Master's Degree at China University of Mining and Technology. His main research topics are Surrounding rock support of roadway in deep mining.

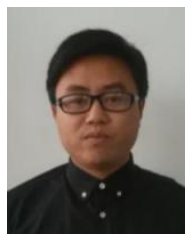

PengWu, is currently studying for Doctor's Degree at China University of Mining and Technology. His main research topics are Rock mechanics of mining and slope stability.

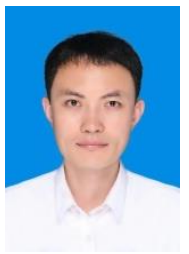

Dr. Liang Chen, is a Lecturer works in China University of Mining and Technology. He got his Master's Degree of Mining Engineering from China University of Mining and Technology, and got his Doctor's Degree of Engineering from China University of Mining and Technology. His current research topics are Rock mechanics of mining.

Citation: Zhiwei Feng, (2020)" Study on the Instability Mechanism of Large Dip Roadway in the Coal Seam”, International Journal of Mining Science (IJMS), 6(4), pp. 1-15. DOI: http://doi. org/10.20431/24549460.0604001

Copyright: () 2020 Zhiwei Feng, This is an open-access article distributed under the terms of the Creative Commons Attribution License, which permits unrestricted use, distribution, and reproduction in any medium, provided the original author and source are credited. 